\title{
EL CINE COMO FUENTE PARA LA HISTORIA. IBEROAMÉRICA Y EL CINE NORTEAMERICANO.
}

\author{
Juan Aquilino Cascón Becerra \\ Universidad de Cádiz
}

\section{$\underline{\text { RESUMEN }}$}

Este artículo recuerda la importancia del Cine como fuente de investigación histórica y como recurso didáctico que ofrece al historiador múltiples puntos de vista sobre un hecho histórico, una época, una sociedad... Los EE.UU., la potencia de las Américas, muestra en sus películas su visión sobre la Historia de Iberoamérica. En este cine tan dinámico como comercial, el historiador descubre tópicos, versiones oficiales, críticas al imperialismo, etc.

Palabras clave: Cine, Historia, Iberoamérica, investigación, recursos didácticos.

\section{$\underline{A B S T R A C T}$}

This article shows the importance of cinema as source for historic research and as didactic resource which offers to the historian differents points of view about an historic episode, an epoch, a society... U.S. Americas' potency shows in their pictures his own vision about Latin America's History. In this cinema as dinamic as commercial, the historian discovers topics, officials versions, critiques to the imperialism, etc.

Keywords: Cinema, History, Latin America, research, didactics resources.

\section{Cine para no olvidar}

En una entrevista recientemente publicada por el diario $E l M u n d o o^{\prime}$, el director de cine Martin Scorsese $e^{2}$ hablaba sobre un interesante proyecto cinematográ-

\footnotetext{
'Entrevista de Rubéll Amon, enviado especial a la Mostra de Venecia. Publicada en el diario El Mundo, el maries 4 de septiembre de 2001. En la misma, Scorsese declara que "enriquece más el pasado o la conciencia del pasado. Creo que uno no puede ser un buen cineasta o un buen espectador si no ha visto Ladrón de bicicletas o si desconoce el cine de Kurosawa o de Bergman. No digo he ho se haga un mal cine. Digo... que no se tiene una conciencia sólida del pasado y que predomina demasiado el punto de vista teórico. Da la impresión de que muchas directores nos cuentan cómo es la vida sin haberla vivido, sin emociones, asépticamente."

${ }^{2}$ Martin Scorsese (Nueva York, 1942) rodó su primer largometraje, Who's that knoching at my door, en 1967. Tras su primer éxito con Malas calles 1973, ha dirigido películas como Taxi driver 1973, New York, New York 1977, Toro salvaje 1979, La última tentación de Cristo 1988, La edad de la inocencia 1993, Casino 1995...
} 
fico. Este realizador italoamericano promueve una fundación para recuperar las películas antiguas olvidadas en los archivos de las multinacionales, algunas, verdaderas joyas del patrimonio universal de la Humanidad. Cuenta con el apoyo de "grandes" como Woody Allen, Clint Eastwood o Spielberg. Scorsese se siente orgulloso de haber "redimido" un film rodado en Nueva Jersey hace 70 años titulado Santa Maria Luntana, que cuenta la intrahistoria de la inmigración italiana a los EE.UU. Sobre este film dice que "...He reconocido mi propia historia, la historia de mi familia, que vino hasta Nueva York para encontrarse con un mundo nuevo, con todas las inquietudes que eso supone. El filme está rodado en Nueva Jersey, que para los italianos pobres, como nosotros, era una especie de paraiso, de oasis...cuando vi Santa Maria Luntana me acordé de mis abuelos, de mis padres, de mi pasado. Me acordé de aquella aventura memorable."

En la misma entrevista, Scorsese reconoce la necesidad de proteger ese patrimonio cinematográfico a toda costa, llamando a un mayor compromiso social e institucional: "El cine ha sido uno de los grandes espejos de la humanidad en el último siglo, asi es que resulta imprescindible tener conciencia de ese patrimonio...para saber cómo éramos, para conocer nuestra identidad." Director eminentemente comercial, habla sobre la conveniencia de conjugar el "espectáculo" con lo antropológico e histórico: "El cine tiene que entrañar un estímulo intelectual, pero siempre acompañado del entretenimiento. Las películas del neorrealismo italiano, por ejemplo, eran entretenidas en la medida en que te transmitian una emoción y en la medida en que te consentian identificarte rápidamente en la pantalla."

Esta entrevista no descubre nada nuevo, pero viene a recordar una vez más el inigualable valor que tiene el cine para el historiador y para la Historia como fuente, como documento histórico de enorme valor antropológico, social y, casi, arqueológico, sobre todo a la hora de abordar la historia del siglo XX, y los próximos. Al fin y al cabo, se podría considerar que ése siglo empieza cuando a fines del XIX nace la primera película de la historia de la mano de los franceses Louis y Auguste Lumière.

Pero Scorsese no sólo recuerda el valor del cine como documento para una Historia oficial, de tintes épicos y tópicos, sino que en la entrevista se centra en la relación entre cine e Intrahistoria, con el peso que ésta tiene como memoria de todos, incluyendo a los sectores sociales más olvidados por la historiografia oficial. Otra manera que tiene el cine de incrementar su valor intrínseco. Además, sostiene la necesidad de que dicho cine sea entretenido, que llegue a cualquier espectador; con esto se convierte en un instrumento didáctico de primer orden 
para el historiador, pues agiliza $\mathrm{y}$, en cierto modo, hace atractivo el descubrimiento y la investigación de la Historia.

La importancia del cine a todos los niveles es hoy en día un hecho innegable. Socialmente dicha importancia queda reflejada en el tiempo y espacio que los medios de comunicación de $\operatorname{masas}^{3}$ (de la prensa a la televisión pasando por una aún incipiente red de Internet) dedican al "universo" del cine. Cada vez cobran mayor prestigio los grandes festivales de cine, verdaderos eventos sociales y políticos para las ciudades que los acogen. La proliferación de dichos festivales ${ }^{4}$ recuerda que detrás de ciertas pretensiones artísticas y del "glamour" promovido, existen unos intereses económicos enormes, evidentes sobre todo en el cine norteamericano y cada vez más en el europeo. En otras partes del globo el cine maneja cantidades astronómicas, como es el caso de la India.

Otro aspecto revelador del peso del cine es su relevancia como medio de expresión artística. Con el nacimiento del cine surge un nuevo lenguaje sin antecedentes técnicos, en una época de grandes avances tecnológicos decisivos, al tiempo que revoluciona el panorama de las artes plásticas. Simple espectáculo de barraca de feria en un principio, el cine logrará, con el transcurso del tiempo, establecer una sutil relación con la literatura, el teatro y más tarde, la televisión. Esta relación se mueve entre una clara diferenciación y cierta simbiosis; aquí se podría incluir la relación del cine con la fotografia e incluso con un tipo de expresión artística que nace al mismo tiempo que el cine, la historieta o cómic ${ }^{5}$ (interesante relación se da, por ejemplo, entre el spagetti-western y los cómics undergrounds de los 70), relacionado a su vez con el Pop-art.

Pето para el historiador el cine cumple sobre todo dos funciones: las de documento histórico que refleja los avatares de la humanidad o de determinadas

\footnotetext{
${ }^{3}$ Tras la crisis del sistema económico capitalista de los años 70 , se idea como salida a esa crisis una econornía que sigue siendo capitalista pero que utiliza los medios de comunicación y las tecnologias de la información (entre ellas, la red Internet) como estrategia central.

" Su número es cada vez mayor, con una variada gama que va de los más famosos (Mostra intemazionale d'arte cinematografica de Venecia, Festival international du film de Cannes, Film-Festspiel de Berlín) hasta los más desconocidos por el gran público (Festival de Cine Iberoamericano de Santa Cruz, Bolivia), pasando por los especializados: de animación (Annecy, Varna, Ottawa), de cortometrajes (Oberhausen, Lille, Brest), de documentales (Nyon, Leipzig), independiente (Sundance), de cine fantástico y ciencia-ficción (Avoriaz, Sitges, Trieste), eróticos (Barcelona)... En España destaca el Festival de cine de San Scbastián, iniciado en 1953, al que hay que añadir los de Huelva, Valladolid, Las Palmas, Málaga, Elche, Gijón, Orense, Peñiscola... y esto sin contar las igualmente numerosas muestras de cine: Valencia, Cádiz, las dedicadas al cine latiıoamericano de leérida y Vigo, etc.

'El 28 de diciembre de 1895, en el Gran Café de París, los Lumière presentaban la película La salida de los obreros de una fábrica (era la Factoría Lumière). Precisamente el mismo año en que Foutcault da vida a su personaje Yellow Kid, considerado el primer cómic de la Historia, en las páginas del suplemento dominical del diario New York World de J. Pulitzer. Al mismo tiempo aparecían en Alemania Max und Moritz, personajes creados por W. Busch.
} 
sociedades; y la de eficaz instrumento didáctico ${ }^{6}$ para los docentes que abordan cualquier etapa histórica, pero en especial, el decisivo siglo XX.

Como instrumento didáctico el cine muestra una significativa variedad de elementos que realzan su importancia pedagógica. Obviamente, es valioso por lo que cuenta: cualquier episodio o personaje histórico, o etapa de la Historia llegan al alumnado a través de cualquier película "histórica" de tipo convencional, simple relato de unos hechos aderezados con poco más, usualmente con poca visión global de esos hechos y casi nula visión crítica de los mismos. En este apartado abundan las simples traslaciones al cine de la historiografía oficial y/o tradicional. El rasgo que mejor define en mi opinión al cine como instrumento didáctico es su capacidad de síntesis. En alrededor de las dos horas que dura la mayoría de las películas se reflejan procesos históricos que duraron siglos, episodios que duraron meses, años... e incluso modos de vivir y pensar tan efimeros como una moda o tan duraderos como aquellas tradiciones que se pierden en la noche de los tiempos.

Otro rasgo es la gran capacidad que tiene para conectar directamente con el público/alumnado, por medio de un lenguaje sobre todo visual, y que aúna lo ya citado por Scorsese: esa mezcla de entretenimiento y reflexión intelectual. Evidentemente, las películas que mejor combinen ambas facetas serán las más indicadas para la labor del docente (incluso para la del investigador). Otro rasgo sería la rica variedad de puntos de vista, de enfoques que hay en cada film que trate sobre un mismo tema o personaje ${ }^{7}$. Se pueden encontrar películas apologéticas, "hagiográficas" junto a otras muy críticas o desmitificadoras; opuestas visiones políticas o historiográficas junto a películas bajo el personalísimo prisma de su autor; versiones humorísticas, patrióticas o patrioteras, nacionalistas, filosóficas, reaccionarias, humanistas, meramente visuales, poéticas... Todo ello necesario para conocer las muy diversas caras de la Historia del complejo ser humano, para apreciar las tendencias ideológicas ( $\mathrm{y}$ lo tendencioso de cada ideo-

\footnotetext{
- En España el gran defensor del Cine como materia obligada dentro del aula es el historiador del cine Román Gubern. Considerado uno de los gurús de la comunicación en Europa, Gubern es catedrático de Comunicación Audiovisual de la Universidad Autónoma de Barcelona, guionista y escritor. Su obra El eros electrónico2000, sobre la evolución de las artes visuales hasta la llegada de la realidad virtual, es una muestra más de la importancia de sus escritos para el historiador que desee aproximarse al mundo del Cine.

'Esa variedad de enfoques se percibe, por ejemplo, en las diversas películas que hay sobre uno de los personajes históricos más relevantcs, Jesucristo: Intolerancia 1916, de D. Griffith; Cristo 1917, de G. Antanamoro; Rey de Reyes 1927, de Cecil B. De Mille; Rey de Reyes1961, de Nicolas Ray; El Evangelio segrin San Mateo 1964, de P.P. Pasolini; La historia más grande jamás contada 1965, de G. Stevens; Proceso a Jesiis1973, de J.L. Sainz de Heredia; Godspell 1973, de D. Greene; Jesucristo Superstar 1973, de N. Jewison; Jesís de Nazaret 1977, de F. Zeffirelli; La última tentación de Cristo 1988, de M. Scorsese; Jesús de Montreal 1989, de Denis Arcand; La vida de Brian 1979, de Terry Jones; El hombre que hacia milagros 1999 , de S. Sokolov y D. Hayes...
} 
logía) y las distintas voces y miradas existentes en la realidad y no siempre llevadas a la pantalla, como ya recordaba Scorsese con su film sobre los emigrantes.

\section{El Cine como documento histórico}

Sobre el cine, llegó a decir el francés Pierre Mac-Orlan: "...el cine es un arte admirable: incluso es el único arte que puede reflejar literalmente nuestra época... con todos sus ritmos secretos... El cine permite traducir fielmente la psicologia de nuestro tiempo. Incluso podriamos decir que el arte cinematográfico fue hallado por instinto, para asi poder dotar a la época de su único medio de expresión". Tan acertada reflexión no es reciente; data de 1923, cuando aun quedaba "casi todo" por ver, en el cine y en la realidad: Auschwitz e Hiroshima, Gagarin y Armstrong, Olduvai y los más recientes descubrimientos sobre el ADN... por citar sólo algunos ejemplos. Haciendo un muy sucinto repaso por la historia del Séptimo Arte, se comprueba cómo ha sido un testigo de excepción de su tiempo.

La primera película de los Lumière, sobre la salida de los obreros de una fábrica, daba ya al cine un papel de cronista social ${ }^{8}$. Frente a la tendencia fantástica iniciada por Meliès, los Lumière iniciaron la realista, la en principio más interesante para el historiador. Surge con los primeros años la vital El nacimiento de una nación 1916, de Griffith. Tras la I Guerra Mundial, al tiempo que se desarrolla un cine meramente comercial de entretenimiento, sobre todo en EEUU, en Europa surgen movimientos acordes a los acontecimientos vividos durante esos años: es el tiempo del Cine revolucionario soviético (Eisenstein, Pudovkin, Ducvenko), el Impresionismo francés (Delluc, Epstein) al que seguiría el cine surrealista (Buñuel-Dali), y el Expresionismo germano (Wiene, Murnau, Lang, Pabst). Tras la crisis de 1929, surge en EEUU un cine más crítico con la realidad imperante (Luces de la ciudad 1931, de Chaplin) pronto frenado por la censura que imponía desde 1934 el Código Hays, cuyo fin era la presentación de la socicdad norteamericana como modelo de justicia y "paz" social... en unos años en que en la vieja Europa triunfaba el fascismo y el nazismo, con productos filmicos de propaganda nacionalista y belicista. Al mismo tiempo se daba en Francia el Realismo Negro, también denominado Naturalismo poético (Vigó, Clair, Renoir), con un interés por la realidad de las clases más empobrecidas y marginales.

\footnotetext{
^ El socialista francés Jean Jaurès llegó a decir que el cine era el teatro del proletariado. Curiosamente, la que se podría considerar la primera película rodada en España, también trataba sobre otra salida: La salida de misa de doce del Pilar de Zaragoza 1897, de E. Gimeno...
} 
Con la Il Guerra Mundial se desarrolla un cine bélico-patriótico junto a otro de tipo evasivo destinado a las masas. Será sin embargo más interesante, desde una óptica teórica, el surgimiento de un cine documentalista a partir del trabajo de los reporteros de guerra (Escuela Documental Británica). Con la posguerra, y hasta nuestros días, surgen una serie de movimientos que destacan por su sensibilidad sociohistórica. Es el caso del imprescindible Neorrealismo italiano (Rosellini, De Sica, Visconti...), que será tratado más adelante, o la Generación perdida estadounidense (Rosen, Kazan, Zinnemann), cuya sensibilidad social chocó con la "caza de brujas" del maccarthismo, en los años en que se clausura la Escuela Documentalista de Nueva York, y Welles y Chaplin deciden exiliarse de la nación que abandera la libertad. Será tras esa época Wilder el gran crítico de la sociedad neocapitalista en EEUU.

En Europa surgen en los años 50 dos movimientos con incuestionable interés por la problemática del individuo y la sociedad, por la Intrahistoria. Por un lado, en Gran Bretaña, nace el Free Cinema, cuyos principios (manifiesto de los angry young men) eran el retorno a las fuentes del documental y la problemática social, reflejando la vida cotidiana y marginal'. En Francia, a raíz de la política cultural impulsada por A. Malraux, se origina en 1957 la Nouvelle Vague, caracterizada por su temática arriesgada y anticonvencional, su sentido crítico y por aproximarse al documental. Organizado en torno a la prestigiosa revista Cahiers du Cinéma, el grupo incluía a nombres como los de F. Truffaut, J.L. Godard, E. Rohmer y C. Chabrol $^{10}$. Uno de los últimos movimientos cinematográficos es el incipiente cine Dogma. Surgido a mediados de los noventa, su carácter experimental, cercano al documental, puede hacerlo interesante a la hora de abordar temas relacionados con la Intrahistoria', aunque aún no parece haber superado al cine documental.

El Cine como documento histórico ofrece, además de una labor testimonial de su tiempo, la de instrumento que refleja la visión que se da (oficialmente o en "la calle") sobre una determinada época o acontecimiento. A lo que se añaden reflexiones sobre un tema más específico: el poder, las relaciones humanas, la ideología, la violencia, etc... e incluso la simple propaganda de la ideología oficial, lo "política-

\footnotetext{
"Destacan filmes como Mirando hacia atrás sin ira1958, de T. Richardson, Sábado por la noche y domingo por la mañana1959, de K. Reisz, o El ingenuo salvaje 1963, de L. Anderson.

${ }^{10}$ Buena muestra del cine de los autores de tal movimiento galo son las peliculas: Los cuatrocientos golpes 1959, Jules et Jim 1961, Farenheit 451 1966, y La noche americana 1973, de Truffaut; Ma nuit chez Maud 1969 y Le genou de Claire 1970, de Rohmer; Al final de la escapada 1959, El desprecio 1963, Pravda 1969, Nouvelle Vague 1990, de Godard; El bello Sergio 1958, Doble vida 1959, Las ciervas 1968, La ceremonia 1995, de Chabrol.

"Con el manifiesto Dogme 95 se inicia la historia de este colectivo de directores fundado en Dinamarca en 1995. El grupo, liderado por Lars Von Trier, incluye a nombres como K. Levring, T. Vinterberg y S.K. Jacobsen. En su manifiesto Dogme 95 se criticaba al cine "burgués", a la decadencia de la Nouvelle Vague, y se abogaba por un cine más "democrático".
} 
mente correcto", no siempre acorde con la realidad imperante. Casi cualquier película puede servir al historiador, hasta la más comercial. Incluso un género tan irreal como es la ciencia ficción puede informar de la imagen que se tiene del futuro en una $u$ otra época ${ }^{12}$. Para rizar el rizo se encuentran las películas "de desastres", género normalmente de serie B que, tras los recientes atentados terroristas de Nueva York y Washington, se revalorizan para el historiador porque transmiten algo más que las costumbres o la ideología de una sociedad: estos filmes muestran los miedos más larvados, los fantasmas del subconsciente colectivo - que de modo magistral analizó Jung - plasmados en catástrofes ficticias y, de manera involuntaria, proféticas ${ }^{13}$.

Si para muchos autores el primer gran film que se emplea como retrato histórico es El acorazado Potemkin 1925, lo cierto es que las películas "histónicas" de variable calidad son abundantísimas en todas las épocas y países. No obstante, es con el Neorrealismo italiano posterior a la II Guerra Mundial donde se alcanza una mayor riqueza artística que conjuga con una crónica de la realidad cotidiana, sin eludir el lado más triste de la vida: el hambre, el paro, los niños abandonados, los anti-héroes... El cine es concebido aquí ante todo como testimonio documental.

El padre de la escuela fue Rossellini, quien inició este movimiento con el filmmanifiesto Roma, ciudad abierta 1945. Rodado con escasez de medios, en el film las escenas fueron filmadas en los mismos lugares donde ocurrieron los hechos acontecidos pocos meses antes. Analizando la resistencia de humildes italianos ante el invasor nazi, se retrata una galería de personajes heroicos alejados de los cánones convencionales, todo un ejercicio de Intrahistoria. Los héroes no son brillantes generales ni esforzados partisanos, sino niños, mujeres obreras, un cura... El alma del

\footnotetext{
${ }^{12}$ Basta con recordar la variedad de "futuros" que nos ha mostrado la gran pantalla: desde Metrópolis 1926, de Lang, film de marcado tinte social y revolucionario, hasta otros como La figga de Logan, la revalorizada El planeta de los simios, las filosóficas 2001. Odisea en el espacio y Blade Runner la apocaliptica Mad Max. o las recientes Gattaca e Inteligencia Artificial, filmes condicionados por los últimos avances técnicos y genéticos, pero cuyo argumento, en el caso del film de Spielberg, parece tan viejo como la fábula de Pinocho...

1 Películas "proféticas" sobre el atentado del 11 de septiembre de 2001 son hoy El coloso en llamas 1974, Amanecer rojo 1984, Independence Day 1996 y su parodia Mars Attack!1996, sin contar con las abundantes del mismo género de los años 70 . Filmes sobre terroristas tampoco faltan en el más comercial cine "made in Hollywood": en Regreso al fituro 1985, los "tnalos" eran unos terroristas libios, en un tiempo de máxima tensión entre Washington y la Libia de Gaddafi... terroristas árabes cran el enemigo de Schwarzeneger en Mentiras arriesgadas, film de mediados de Los 90. Tambièn en la misma línea se hallan Estado de sitio 1999 o Air Force One 1997. Si ei reciente atentado ha sido comparado con el ataque a Pearl Harbour de 1941 ("el día de la infamia") puede que se deba al reciente estreno del filtm homónimo de Michael Bay... Hollywood, sin pretenderlo, había previsto la catástrofe, pero la describió mejor que la TV, pues ésta no mostró cadáveres y sí mucha voz en "off". El cine supo contarlo mejor pero, paradójicamente, tal acontecimiento ha supuesto una grave crisis para la industria cinematográfica, en especial para el cine de catástrofes; la TV, que se anticipó a Internet al retransmitir en directo los hechos, alcanzó sin embargo índices de audiencia insuperables hasta la fecha en todo el planeta...
} 
grupo neorrealista fue el escritor y guionista Cesare Zavattini, y los principales autores, los católicos Rossellini y De Sica y los marxistas Visconti y De Santis ${ }^{14}$. Quizás el film más relevante del movimiento dentro y fuera de Italia es Ladrón de bicicletas 1948, de V. De Sica. A partir de 1951 se vuelve a lo anterior; Zavattini declara que no se ha realizado nada realmente neorrealista, piensa que el director debe tender a sustituir la representación de la realidad por la realidad misma, surgiendo así los filmes-encuesta, que son más documental que película en sentido convencional.

Dentro del cine como testimonio histórico se pueden distinguir cuatro perspectivas bien diferenciadas. Una es la del cine de simbolismo social, de denuncia política y descripción de grupos sociales: El Gatopardo 1962, La caida de los dioses 1969, Confidencias 1972... Visconti declarará: "No se puede ser hombre $y$ mucho menos artista, sin tener una conciencia politica. El arte es politica". Otra perspectiva es la del cine de episodios históricos, cuyo rasgo primordial es su enfoque directo y su posicionamiento político: aquí destaca sobre todo $Z 1968$, de Costa-Gavras, sobre el asesinato del pacifista Lambrakis en Grecia, pero también Sacco e Vanzetti 1971 y El delito Matteotti 1973.

Otra es la del cine documental o de combate. Aquí hay que recordar La batalla de Argel 1966, de Gillo Pontecorvo, pero sobre todo, la fundamental La batalla de Chile, la lucha de un pueblo sin armas 1975, de P. Guzmán, dividida en dos partes: La insurrección de la burguesía y El golpe de Estado. Film riguroso y básico para una aproximación a la Historia contemporánea de Iberoamérica. Por último, la perspectiva que nos da el cine de grandes síntesis históricas, iniciado con El nacimiento de una nación 1916, de Griffith, y continuado en obras como La tierra de la gran promesa 1975, de Wagda o la ambiciosa Novecento 1976, de Bertolucci.

\section{Cine norteamericano e Historia iberoamericana}

La importancia del Cine hace que sea, como cualquier otro medio de comunicación, vigilado muy de cerca por el poder. En EEUU, desde aquellas feroces campañas en la prensa durante la Guerra de Cuba hasta la actual situación cuasibélica con Afganistán, los medios más poderosos y vistos del planeta han sido manipulados por los poderes fácticos (como en cualquier país del globo) para res-

\footnotetext{
14 Las principales obras son: Roma, ciudad abierta 1945, Paisà 1946, Germania, anno zero 1947, de Rossellini; El limpiabotas 1946, Ladrón de bicicletas 1948, Milagro en Milán 1950, Umberto D 1951 , de V. De Sica; La tierra tiembla 1948, Bellísima 1951, de Visconti; Arroz amargo 1949, de G. De Santis; El camino de la esperanza 1950, de Germi. Después de 1951 se pueden incluir obras como Rocco y sus hermanos 1960, de Visconti; Los inútiles 1953, La strada 1954, de Fellini; Dos mujeres 1960, de De Sica.
} 
ponder a muy distintos intereses; el cine no escapa a esta norma. Lo mismo sirve para adormecer conciencias que para enaltecer/regular ánimos colectivos. En la rica historia del cine norteamericano se dan varios casos elocuentes sobre esa relación entre este medio y el poder de una nación autonombrada como garante de la libertad y la democracia.

Tres ejemplos sobre lo dicho: En 1934 entra en vigor el "Código Hays", el cual impone a las "grandes" como R.K.O., Wamer, Metro o Fox una censura destinada a que en la pantalla la sociedad estadounidense se presente como modelo de confort, justicia, paz social... en unos años de dura crisis, sobre todo en el mundo rural de la América profunda. Se promocionan comedias de Capra y musicales. Después de 1945, el cine de 1a "generación perdida" (Kazan, Rosen, Huston...), de crítico realismo, es denunciado como subversivo por Mac Carthy y su Comisión de Actividades Antiamericanas, dándose una auténtica caza de brujas. El tercer ejemplo es un artículo publicado el 6 de septiembre de este año por el diario $E l$ Mundo con un rotundo titular: El Pentágono manipula a Hollywood. En dicho artículo se cuenta cómo la industria del cine altera el argumento de sus películas a cambio de tener acceso a instalaciones militares y armas, de modo que los estudios puedan ahorrarse millones de dólares. Para el ejército es una eficaz manera de propaganda: cuando Top Gun, film protagonizado por Tom Cruise, se estrenó en EEUU, la Marina instaló casetas de reclutamiento en los cines. Igualmente los militares se oponían a colaborar en filmes como Forrest Gump, donde un bobo soldado enseñaba el trasero al presidente, o Independence Day, porque según el departamento de Defensa, "las Fuerzas Armadas parecen impotentes e ineptas; todos los logros obtenidos en la lucha contra los alienígenas se deben a acciones emprendidas por civiles"1s.

¿Cuál es, entonces, la importancia del cine norteamericano como medio de estudio de la Historia iberoamericana? Si tenemos en cuenta que no sólo las grandes obras del Neorrealismo u otras de similar calidad plástica, sino que igualmente otras películas "menores" de peor calidad, pero muy comerciales y con gran tirón entre el gran público, pueden ser estudiadas por el historiador, se verá claramente esa importancia. Estos filmes, accesibles con facilidad, tienen una enorme repercusión entre ese gran público de cualquier continente y país, a diferencia de las obras al gusto de los a veces caprichosos críticos especializados. Repercusión que se palpa al crearse una determinada opinión, siendo también un cine que refleja la opinión del propio público.

\footnotetext{
${ }^{15}$ Es significativa la diferencia de calidad y enfoque critico entre algunos filmes que han obtenido colaboración (Potton 1970, Top Gun 1986, La caza del Octubre Rojo 1990, Juego de patriotas 1992, Armageddon 1998, Pearl Harbor 2001...) y los que no la obtuvieron: Apocalypse Now 1979, Platoon 1986, La chaqueta metálica 1987, Memphis Belle 1990, La teniente O'Neill 1997, La delgada linea roja $1998 \ldots$
} 
No es éste un cine "inocente", sólo de evasión; en él se pueden leer entre líneas mensajes que de modo inconsciente calan entre el público. Ejemplo de esto es la curiosa coincidencia entre el estreno reciente de Trece dias, film sobre la crisis cubana de los misiles... 40 años después! con el estreno en geopolítica de G.W. Bush y su polémico escudo-paraguas nuclear, que en su día "resucitó" el clima de Guerra Fría superado tras una década del fin de la URSS. Hoy, con la aparición en primera plana del terrorista internacional Ben Laden como nuevo antagonista satánico de Washington (Sadam Hussein pasó de moda), no sorprende el que los "malos" de los filmes más comerciales de los últimos años sean casi siempre terroristas árabes, aunque en la realidad alguna que otra masacre fuera obra de norteamericanos WASP: Waco, Oklahoma... El cine contribuye a la construcción de futuros enemigos (mientras la CIA les proporciona cobertura y armas en la realidad), para una nación-imperio grandemente beneficiada por las principales guerras del último siglo.

Pero este cine, destacado por estas características de comercialidad y estar muy directamente dirigido al gran público, es además, destacable por dos funciones específicas: su alta capacidad pedagógica por las características citadas, y por cumplir la función de ser el contrapunto al cine iberoamericano, por su complementariedad. El estudio de la Historia necesita la mayor cantidad posible de información, de diversidad de fuentes, de ópticas variadas y de distintas voces y miradas más allá de historias oficiales, a veces apolilladas por tópicos, demasiado anquilosadas y poco atractivas para su estudio en las aulas.

Dentro de esa complementariedad hay que recordar los rasgos diferenciadores del cine iberoamericano. Es éste un cine cuyo rol ha sido el de "hablar" con voz propia; voz mestiza, pues es un cine que mezcla elementos propios con otros tomados de lo más destacado del cine europeo o norteamericano ${ }^{16}$. Cine con gran contenido crítico, cuyo papel primordial es el de convertirse en memoria "cinematográfica" de un colectivo humano exuberante en número, variedad étnica y complejidad cultural únicas en el planeta. Mientras el cine norteamericano coloniza culturalmente el mundo con su peculiar visión/visiones de los hechos, el cine iberoamericano igual denuncia la injusticia como fortalece las identidades más marginadas, según aclara el libro de elocuente título "La memoria filmada. América Latina a través de su cine", obra del grupo de investigación "Intrahistoria y Oralidad" de la Universidad de Cádiz.

El cine norteamericano aporta una capacidad de medios, grandes estrellas, un lenguaje más comprensible para el gran público y una agilidad narrativa de la

\footnotetext{
${ }^{16}$ Dentro del cine iberoamericano se observan una serie de rasgos muy típicos, como la persistencia de ciertos temas (el padre ausente), una característica narrativa heredada de cosmovisiones prehispánicas: el eterno retorno insertado en historias circulares, cíclicas, etc... junto a elementos tomados de otras latitudes, como por ejemplo, la fuerte influencia del Neorrealismo tialiano o del surrealismo de Buñuel.
} 
que suele carecer el cine iberoamericano. Añade a esto una visión peculiar, entre desmitificadora y llena de tópicos, con gran capacidad de síntesis y con una reflexión sobre los hechos narrados que deja ver la opinión del norteamericano medio, de los poderes fácticos o de voces alternativas o críticas dentro de la sociedad estadounidense sobre la realidad de América latina.

A través de la historia de este cine estadounidense que ha abordado la Historia de los países al sur del Río Grande, se observa una mezclada visión natural entre cercana y lejana de los EEUU y el resto de América. Lejanía en lo cultural, lo lingüístico, y cercanía en lo geográfico e histórico, por el continuo papel de potencia "regional"(o hemisférica) siempre interventora en los asuntos económicos y políticos iberoamericanos. El cine fue desde sus inicios un elemento propagandístico de gran alcance, como demuestran las tareas documentalistas de la Biographe Company sobre la Guerra hispano-estadounidense, de clara tendencia nacionalista; o como se observa en los documentales sobre la Revolución Mexicana, en los que un astuto Pancho Villa "convirtió" en aliados a los camarógrafos gringos, erigiéndose gracias a los avances de su ejército en un héroe real de la gran pantalla para los norteamericanos... hasta su ataque a Columbus.

Por lo demás, la historia de este cine corre paralela al del conjunto del cine norteamericano, y corre paralela a la concepción que se tiene de la Histona en general y a determinados episodios de la misma en particular. Aquí se debe recordar que lo más común en este cine es dar prioridad a la recreación de episodios muy concretos; es más raro encontrar grandes síntesis históricas, abundando más un concepto clásico-tradicional de "héroe", con largometrajes como Juárez, Viva Zapata!, Che!, Romero... se mantiene pues una narración tradicional de la Historia, contada a partir de la vida de los prohombres. Esta forma tradicional de representar la Historia es más común en los filmes más antiguos. Es el caso de Juárez, film de 1939 dirigido por W. Dieterle y protagonizado por Paul Muni y Bette Davis, cuyo argumento, lejos de narrar la trayectoria vital y política del estadista mexicano, se centra casi exclusivamente en la dicotomía creada entre Juárez y su oponente Maximiliano de Habsburgo. La cinta, basada en la obra de teatro y novela "The phantom Crown", da al emperador títere más protagonismo que al propio Juárez. El film, que sirve de burda caricatura del emperador francés Napoleón III, intervencionista fuera de Europa (Argelia, Indochina, México) y enfrentado, pues, a la Doctrina Monroe, se estrena el mismo año en que Hitler invade Polonia. En la película una decadente Europa enemiga de la democracia se enfrenta a unos EEUU de inigualable talla moral (Lincoln), que les lleva en la realidad, a trasladar al Viejo Mundo su política del Big Stick. Juárez no transmite tanto la situación real del México de mediados del XIX como recrea un cule- 
brón lleno de intrigas palaciegas y cierto endiosamiento del carismático dirigente zapoteca.

Casi la misma línea se mantiene con el largometraje El capitán de Castilla, dirigido por $\mathrm{H}$. King y protagonizado por Tyrone Power. Film de los años $50 \mathrm{del}$ género de "capa y espada", en el mismo abundan los tópicos anglosajones sobre lo español o hispano. El protagonista se enrola en la expedición de Cortés rumbo al corazón del imperio azteca tras huir en España de la Inquisición. Los tópicos de la Leyenda Negra, surgidos de la propaganda antiespañola de los años de enfrentamiento entre Felipe II y la Europa protestante (Isabel I) han demostrado la eficacia de dicha propaganda al perpetuarse hasta nuestros días. Sirve de ejemplo 1492. La conquista del Paraiso 1992, dirigida por el especialista en grandes espectáculos visuales Ridley Scott (Alien 1979, Blade Runner 1983, Gladiator 2000) y con G. Depardieu como Colón. Scott plantea de forma maniquea una oposición entre Paraíso e Infierno donde aquél es un edénico Nuevo Mundo, y lo infernal, el Viejo, en concreto, la Castilla del momento. En la cinta Colón recorre a duras penas calles abarrotadas del gentío que asiste a espeluznantes Autos de Fe. Al menos, la película sí muestra una óptica actual al proyectar una imagen del indio como persona y no como el bárbaro sal vaje de las viejas películas del Oeste.

Otro bello espectáculo visual (las imágenes se basan en ilustraciones de enorme valor antropológico e histórico de misioneros del XVIII en Paraguay), al que se une una BSO de enorme fama y éxito, es La Misión 1986, de R. Joffé, protagonizada por Robert de Niro y Jeremy Irons. Aunque se mantienen algunos tópicos sobre lo hispano (la fiesta, los toros, la religiosidad, el orgullo de los caballeros...) es un film en donde se da también una visión digna de los indios, en este caso los guaraníes, visión heredada sobre todo del discurso sobre el buen salvaje. de los ilustrados del norte de Europa del XVIII, y en menor medida de los españoles que defendieron la dignidad de los indios desde el inicio de la Conquista, como Montesinos o Las Casas: curiosamente sus alegatos a favor de los indios sirvieron en Europa para fortalecer la Leyenda Negra más que para dar a conocer la realidad indígena. Gracias a este film se observa la labor de aquellos que en tiempos virreinales lucharon por la defensa de la dignidad humana y por un acercamiento no hostil entre culturas. Sin La Misión el público mayoritario nunca hubiera conocido la experiencia social y cultural única que fueron las reducciones jesuíticas del Paraguay colonial. El film no aborda aspectos criticables sobre la actuación de los jesuitas sobre los indios, es todo un alegato a favor de su actividad; sí hay un duro ataque a las políticas que desde las cimas del poder afectan y perjudican a los más débiles: en el film, el despotismo ilustrado que se impone injustamente sobre remotos súbditos "de segunda clase", y en el mundo actual las 
políticas macroeconómicas impuestas sobre los ciudadanos del mundo paradójicamente por naciones autodefinidas como democráticas.

Esta característica de dar a conocer algo prácticamente inédito para el gran público como son las reducciones guaraníticas (tras el estreno del film tuvo gran éxito la publicación de libros sobre el tema) también se da en Romero1989, de J. Duigan. El arzobispo salvadoreño Romero, asesinado por paramilitares en 1980 , defensor de los más humildes de su país en tiempos críticos, es el principal mártir de la Teología de la Liberación y un referente dentro de la Iglesia iberoamericana. Antes del film, en Norteamérica y Europa apenas era conocido su nombre fuera de círculos eclesiales y de grupos de cristianos comprometidos, mientras en Centroamérica era, y es, considerado un santo no oficial. Tampoco se sabría muy bien qué es la Teología de la Liberación, tema eludido en cintas comerciales, si bien en Romero se traza más un retrato personal y del país que de la influencia social de la Liberación en América Latina. Al fin y al cabo, Romero fue un jerarca, no un Camilo Torres ni un Ernesto Cardenal. En el film no se critica tanto la responsabilidad de Washington en los desastres del país como se ataca a la élite castrense salvadoreña, el "malo" de la película. Sería interesante la comparación de Romero con otras obras sobre El Salvador: El Salvador: Another Vietnam 1981, de G. Silber y T. Vasconcelos, o Salvador 1986, de O. Stone.

Para destacar la interesante relación que existe entre el cine norteamericano y la Literatura, hay un par de buenos ejemplos: Gringo Viejo 1989, de L. Puenzo, sobre la novela del mismo título del prestigioso escritor mexicano Carlos Fuentes; y Viva Zapata! 1952, de E. Kazan y con guión del Nobel Joln Steinbeck. Ambas casualmente abordan la Revolución Mexicana. En el film de Kazan se trata magistralmente el tema del poder y la condición humana. Nada que ver con Che!1969, de R. Fleischer, cinta de pésima calidad sobre el revolucionario más famoso del siglo XX y que constituye una caricatura de personajes sobre la leyenda negra de Ernesto Guevara.

En Viva Zapata! Kazan va más allá de la mera descripción del personaje; incluso más allá de contar una "fábula" sobre el poder. Kazan aborda el tema de la llegada del revolucionario al poder, y cómo éste, de forma casi natural imita los errores de los tiranos que ha derrocado para situarse en la cima. Ese fracaso del revolucionario puede llevar al espectador a un razonamiento significativo: es mejor que nunca lleguen al poder los revolucionarios. Se da un planteamiento del poder como algo negativo de por sí que pervierte al que lo detenta. Parece un planteamiento anarquista, pero en realidad hay cierto trasfondo conservador sobre la imposibilidad de éxito para cualquier revolución, denostada además por la violencia que provoca. Hay que recordar que la película es de 1952, poco después de 
que Kazan delatara ante los tribunales de la "caza de brujas" de Mac Carthy a sus antiguos camaradas comunistas de Hollywood. Viva Zapata! puede verse como una forma del director para desmarcarse de toda postura pro revolucionaria, al tiempo que constituye una obra de alta calidad artística por el acercamiento psicológico con que se muestran los personajes.

Otra cinta que trata el tema de la revolución, en este caso, la Revolución Cubana, es Bananas 1971, dirigida y protagonizada por el genial Woody Allen. Su título ya aclara la visión que va a dar sobre el tema. Con su peculiar sentido del humor parodia la revolución de una remota república "bananera", nombre despectivo con el que los norteamericanos han bautizado a muchos países de su patio trasero en manos de compañías multinacionales yanquis. En el film se parodia casi todo: los líderes revolucionarios, la CIA, la solidaria juventud norteamericana, el afán de aventuras guerrilleras... desde su papel de eterno obseso e hipocondríaco Allen se ríe incluso de las torturas y otros desmanes de un estereotipado dictador golpista.

Con mucha mayor seriedad está tratado este tema de los golpes militares y las dictaduras latinoamericanas en Missing (Desaparecido), film del siempre critico Costa-Gavras de 1982, basado en la novela del mismo título de T. Hauser y en hechos reales. La enorme calidad de la cinta hizo que recibiera la Palma de Oro del festival de Cannes. Su argumento se centra en el caso de un joven norteamericano que "desaparece" en los días del golpe militar contra Allende. Para el estudio de las dictaduras del Cono Sur de los 70 es básica, pues da una visión alternativa a cintas "autóctonas" como las argentinas La noche de los lápices 1986, de H. Olivera, La historia oficial 1984, de L. Puenzo, y La deuda interna 1987, de M. Pereira; o las chilenas La batalla de Chile 1975, de P. Guzmán, y Amnesia 1994, de G. Justiniano. Si bien Missing no alcanza el tono crítico que Gavras da a otros trabajos como $Z_{2}$ en él se pone el dedo en la llaga al mostrar dos hechos vergonzosamente eludidos en el plano oficial: el aplauso de la clase alta chilena a los militares golpistas y el apoyo a éstos de la CIA y la Administración norteamericana con ayuda diversa, ya sea apoyo diplomático o con expertos torturadores...

Gavras inserta un conflicto generacional en el argumento como pretexto para mostrar al espectador los horrores del golpe: cadáveres flotando en los ríos, estadios abarrotados de detenidos, morgues con montones de muertos, calles desiertas pobladas sólo por charcos de sangre... Un espectador que se identifica pronto con los personajes que buscan al desaparecido, su esposa, joven desconfiada de los funcionarios norteamericanos, y su padre, un neoyorquino de la generación que aún confiaba en los valores establecidos por el poder y que a lo largo del film 
se va desencantando. Missing, angustiante y magistral, no menciona casi a Pinochet ni a Allende; su objetivo es la denuncia del apoyo de Washington al horror de las dictaduras sudamericanas de los 70, llegando la responsabilidad política a las más aitas instancias, como el consejero de seguridad de Nixon, Henry Kissinger. E1 que fuera Ministro de asuntos exteriores de EEUU entre 1973 y 1977, y Nobel de la Paz en 1973, es hoy en día considerado por muchos colectivos defensores de los Derechos Humanos un candidato firme a ser condenado en el Tribunal de la Haya por sus delitos contra la Humanidad.

Missing es todo un ejemplo de la beneficiosa relación existente entre el Cine, la Historia y la Intrahistoria. En él se aúnan los tres puntos básicos de dicha relación: la importancia de la obra cinematográfica como fuente y objeto de análisis; ser un elemento didáctico útil por su fácil comprensión, comercialidad y accesibilidad; $y$ ofrecer una visión alternativa y complementaria a las historias oficiales de grandes estadistas y políticas macroeconómicas, la Intrahistoria que defendía Scorsese como memoria universal y voz de los más olvidados, de las versiones "periféricas", de al fin y al cabo, con todos sus matices y tonalidades, quizás la auténtica Historia en sí, la de todos. 